\title{
The Psychometric Validation of FCV19S in Urdu and Socio-Demographic Association with Fear in the People of the Khyber Pakhtunkhwa (KPK) Province in Pakistan
}

\author{
Qaisar Khalid Mahmood ${ }^{1}$ (D) Sara Rizvi Jafree ${ }^{2} \cdot$ Waheed Ahmad Qureshi $^{3}$ \\ Published online: 12 July 2020 \\ (C) Springer Science+Business Media, LLC, part of Springer Nature 2020
}

\begin{abstract}
This study rests on two important considerations: the rapid increase of COVID-19 cases in Pakistan and also the marginalization of the people of the KPK province, which would make them more vulnerable in fearing COVID-19. We aim to translate and validate FCV$19 \mathrm{~S}$ into the Urdu language and to identify the socio-demographic associations with fear in the people of the KPK. Using an online Google survey, we were able to sample 501 respondents from the KPK. The Cronbach alpha $\alpha$ value for the Urdu FCV-19S displayed good internal reliability at .846. The unidimensional structure of the FCV-19S in Urdu was confirmed, and all of the items were found to be statistically significant, ranging from 0.59 to 0.80 . The results of the confirmatory factor analysis show that fit indices are all within an acceptable limit. The FCV-19S was also significantly and positively correlated with preventive behavior $(r=.328, p<.01)$ and general anxiety $(r=.458, p<.01)$. The results of independent sample $t$ tests show that women $(t=4.086, p<0.001)$, married people $(t=-2.709, p<.001)$, and unemployed people $(t=-3.199, p<0.001)$ of the KPK experienced great fear of COVID-19. We conclude that that the Urdu version of the FCV$19 \mathrm{~S}$ is a valid and reliable tool and must be used by healthcare practitioners, government bodies, and researchers, to identify the prevalence of fear and to subsequently plan improved social and health policies to reduce anxiety in the public.
\end{abstract}

Keywords COVID-19 $\cdot$ FCV-19S $\cdot$ Psychometric properties $\cdot$ Validity $\cdot$ Urdu $\cdot$ Pakistan $\cdot$ KPK

Qaisar Khalid Mahmood

Qaisar.khalid@iiu.edu.pk

Sara Rizvi Jafree

sarajafree@fccollege.edu.pk

Waheed Ahmad Qureshi

waheedaq@anadolu.edu.tr

Extended author information available on the last page of the article 
COVID-19 cases have increased drastically in Pakistan recently, with numbers estimated at 171,665 as of 20 June 2020. Many argue that the prevalence is even higher due to inefficient governance and low detection. Low levels of reporting are also a consequence of great fear in hospitalization and isolation, mistreatment by practitioners, and facing stigma by society (Waris et al. 2020). Ahorsu et al. (2020) have made an essential contribution by developing a unidimensional scale, FCV-19S, to measure fear of COVID-19 among people in the English language (Pakpour et al. 2020; Ahorsu et al. 2020). Fear of COVID-19 has wide consequences in society (Lin 2020), including low reporting as mentioned earlier, but also an increase in mental distress (Ornell et al. 2020), low commitment to preventive behavior (Pakpour and Griffiths 2020), obsessive compulsive disorder (Fineberg et al. 2020), and discriminatory behavior against infected people (Ramaci et al. 2020). There is also recent worry of an association between the fear of COVID-19 and suicide or suicide ideation (Mamun and Griffiths 2020). Ultimately, unregulated fear of COVID-19 can exacerbate national and global problems related to management of the pandemic.

Khyber Pakhtunkhwa (KPK) is a disadvantaged and conflict-ridden province of Pakistan (Ahmad 2010). As it neighbors Afghanistan, KPK land has been used for the War on Terror, leading to dismal rates of underdevelopment, poverty, and illiteracy (Mehboob 2011). The people of the KPK are known to suffer from lack of attention from the Federal government, provincial political and tribal rivalries and conflict, and inadequate opportunities for livelihood and well-being generally. The area has also been home to one of the largest refugee communities of South Asia due to the war in Afghanistan, adding to issues of unrest and instability (Grare and Maley 2011). Even prior to 9/11, the KPK, previously called FATA, had a history of terrorism, tribalism, and extremism, which has instilled fear and insecurity into the lives of the people living there for decades (Haider and Jameel 2017). Due to a combination of the above-mentioned life circumstances, the people of the KPK suffer from considerable mental health problems related to anxiety and depression (Khan et al. 2015) and identity crisis (Khan et al. 2017). This has built intergenerational insecurities and a lack of trust by the people, contributing to even greater risks of fear and anxiety in the age of coronavirus. In fact, research suggests that the highest incidence of death due to COVID-19 has been reported in the KPK province so far (Waris et al. 2020). It is therefore imperative to investigate the level of fear in the people of the KPK province with regard to COVID-19. With these factors in mind, the aim of this study is twofold: to validate the Urdu version of FCV-19S and to predict the association between the socio-demographic characteristics of the KPK people and their fear of COVID-19.

\section{Methods}

\section{Participants and Procedure}

The researchers used a cross-sectional online-survey to collect data from the KPK, as the pandemic lockdown measures prevented data collection in person. The government of the KPK imposed a lockdown from 25 March 2020, and our data was collected from the 10 to 23 May 2020. We used personal contacts to reach out to the KPK population through social media platforms, such as Facebook, LinkedIn, and Whatsapp. We also used professional contacts by emailing relevant faculties at KPK universities and requesting them to forward the Google survey to their students and colleagues. The respondents were clearly briefed 
about the objectives of the study in a cover letter, and informed consent was taken electronically. The researchers ensured that all of the participants were made aware about the anonymity and confidentiality of their data. No survey could be submitted unless every question had been answered. In total, there were 501 respondents who successfully completed this survey. The respondents were not offered any incentive to participate in this study.

\section{Measures}

In order to see the effect of socio-demographic variables, the survey included questions related to age, gender, educational status, employment status, current place of residence, and marital status.

\section{Fear of COVID-19}

The FCV-19S scale consists of 7-items (e.g., item 2, "It makes me uncomfortable to think about Corona" and item 5, "I cannot sleep because I'm worrying about getting Corona") measured on a 5-point Likert scale. The 5-point Likert-scale ( $1=$ strongly disagree to $5=$ strongly agree) was used to report the responses of the respondents (Ahorsu et al. 2020). The original scale showed extremely good internal consistency $(\alpha=.82)$. The FCV-19S scale has been validated in other languages and is now available in the Italian version ( $\alpha=.87$ ) (Soraci et al. 2020), the Bangla version $(\alpha=.87$ ) (Sakib et al. 2020), the Turkish version $(\alpha=.84)$ (Satici et al. 2020), the Russian version $(\alpha=.80)$ (Reznik et al. 2020), the Arabic version $(\alpha=.88)$ (Alyami et al. 2020), and the Greek version $(\alpha=.87)$ (Tsipropoulou et al. 2020).

In accordance with established protocols for cross-cultural adaptation, the researchers opted for the forward-backward translation method to develop the Urdu version of the FCV-19S scale (Alyami et al. 2020; Yu et al. 2004). In the first phase, the original FCV$19 \mathrm{~S}$ in English was given to an autonomous linguist who was familiar with both languages. The expert translated all of the items into Urdu. In the second phase, one of the authors, who is fluent in English and Urdu, evaluated the Urdu translation and provided feedback to the linguist. After receiving the forward translated Urdu version of the FCV-19S, this scale was again translated back into English by another author who, at this time, was unfamiliar with the original English scale. Both the forward and backward translations of the scale were assessed and evaluated for cultural appropriateness among the authors. A pilot study $(n=27)$ was conducted to see if any changes were required. The findings of the pilot test confirmed that there were no further changes required.

\section{Preventive Behavior Related to COVID-19}

According to available knowledge regarding coronavirus and the recommendations given by World Health Organization (World Health Organization 2020), the researchers developed seven statements to measure preventive behavior related to COVID-19. The items included the following: "I regularly wash my hands for 20 seconds"; "I wear a mask when I go outside"; "I avoid shaking hands as a form of greeting"; "I maintain social/ physical distance while meeting others"; "I avoid people who have a cough or flu"; and 
"I do not touch my face, mouth, nose, or eyes without washing my hands". The Cronbach alpha of this scale was $\alpha=.846$, indicating good internal consistency.

\section{Generalized Anxiety Disorder}

The authors used seven items from the Generalized Anxiety Disorder (GAD) Questionnaire (Spitzer et al. 2006) to measure anxiety disorder among respondents. The seven items used from the scale describe a number of the most salient diagnostic features of GAD (i.e., feeling nervous, anxious, or on edge and worrying too much about various things). Items are rated on a 4-point Likert-type scale ( $1=$ not at all to $4=$ nearly every day). The Cronbach alpha of this scale was $(\dot{\alpha}=.892)$, indicating good internal consistency.

\section{Statistical Analysis}

The authors used IBM SPSS Statistics 21 to perform statistical analyses. Descriptive statistics were used to report the sample characteristics. Measures of central tendency (mean and standard deviation) and measures of distribution (skewness and kurtosis) were calculated with respect to each item. To assess internal consistency of the FCV-19S in Urdu, we computed a Cronbach alpha coefficient $(\alpha)$, inter-item correlations, and corrected item-total correlations. We also assessed concurrent validity of the FCV-19S in Urdu by comparing the Pearson correlations between the FCV-19S and preventive behavior related to COVID-19, FCV-19S, and general anxiety disorder (GAD).

For confirmation of the unidimensional factor structure of the FCV-19S in Urdu, the authors conducted a confirmatory factor analysis (CFA) using the maximum likelihood estimation (MLE) method. AMOS software was used for this purpose. Goodness of fit was assessed according to the following criteria: goodness of fit index $(\mathrm{GFI}<.90)$; adjusted goodness of fit index (AGFI<.90); comparative fit index (CFI > .90); and root mean square error of approximation (RMSEA $\leq .08$ ) (Lei and $\mathrm{Wu} 2007$ ).

\section{Results}

Of the 501 respondents, $293(58.5 \%)$ were male and 208 (41.5\%) were female, with approximately $61 \%$ living in urban areas (Table 1 ). The majority of the participants $(54.5 \%)$ belonged to the age group of 26-50 years followed by $38.9 \%$ who were aged up to 25 years. Most of the respondents were either graduates $(41.5 \%)$ or post graduates $(46.9 \%)$. The study population had almost equal representation of unmarried and married people, and more than half of the respondents $(56.7 \%)$ were unemployed.

\section{Measures of Central Tendency and Distributions}

In Table 2, the measures of central tendency, skewness, and kurtosis of each item are reported. The results indicate that people had agreement with items 1,2, and 5, whereas they disagreed with items 3, 4, 6, and 7. According to Byrne and Campbell (1999), a distribution of items can be considered normal if values of skewness and kurtosis range between \pm 1.5 . Our findings show that all of the items were normally distributed because no item had a higher or lesser value than \pm 1.5 for skewness and kurtosis. 
Table 1 Socio-demographic characteristics of sample, $N=501$

\begin{tabular}{lll}
\hline Variables & Frequency & Percentage \\
\hline Gender & & \\
$\quad$ Male & 293 & 58.5 \\
Female & 208 & 41.5 \\
Age & & \\
$\quad$ Up to 25 years & 195 & 38.9 \\
26-50 years & 273 & 54.5 \\
51 years and above & 33 & 6.6 \\
Marital status & & \\
Not married & 249 & 49.7 \\
Married & 252 & 50.3 \\
Employment status & & 43.3 \\
Employed & 217 & 56.7 \\
Unemployed & 284 & 39.1 \\
Area of living & & 60.9 \\
$\quad$ Rural & 196 & 8.4 \\
$\quad$ Urban & 305 & 46.9 \\
Education & & 41.5 \\
PhD & 42 & 3.2 \\
MSc/M.Phil & 235 & \\
BSc/BSc/BA & 208 & \\
HSSC and below & 16 & \\
\hline
\end{tabular}

\section{Internal Consistency and Concurrent Validity}

The results of the inter-item correlations are presented in Table 3. According to Ferketich (1991), if inter-item correlations and corrected item-total correlations are between .30 and .70, associations between the items are considered as medium to strong. All inter-item correlations were found to be significant and ranged between 0.333 and 0.738 . The value of Cronbach's $\alpha$ equaling .70 or higher indicates acceptable reliability (DeVellis 2016). Cronbach's $\alpha$ for the Urdu version of the FCV-19S was reported as .846 (Table 4). Corrected item-total correlations ranged between .493 and .732. Moreover, the value of Cronbach's $\alpha$ for the Urdu version of the FCV-19S does not go down if any item is deleted from the scale (see Table 4). These results indicate that the Urdu version of the FCV-19S has really good internal consistency. A concurrent validity analysis was also conducted. There was a statistically significant and positive correlation $(r=.328, p<.01)$ between the FCV-19S and preventive behavior related

Table 2 Item properties of the FCV-19S

\begin{tabular}{lllll}
\hline & Mean & Std. deviation & Skewness & Kurtosis \\
\hline 1. I am most afraid of Corona & 3.12 & 1.106 & -.234 & -.724 \\
2. It makes me uncomfortable to think about Corona & 3.29 & 1.091 & -.501 & -.632 \\
3. My hands become clammy when I think about Corona & 2.00 & .913 & 1.064 & 1.313 \\
4. I am afraid of losing my life because of Corona & 2.49 & 1.131 & .447 & -.604 \\
5. When I am watching news and stories about Corona on & 3.41 & 1.129 & -.690 & -.412 \\
$\quad$ social media, I become nervous or anxious & & & 1.059 & 1.155 \\
6. I cannot sleep because I worry about getting Corona & 1.98 & .923 & .676 & -.286 \\
7. My heart races or palpitates when I think about getting Corona & 2.28 & 1.097 & .676 \\
\hline
\end{tabular}


Table 3 Inter-item correlations

\begin{tabular}{llllllll}
\hline & FCV1 & FCV2 & FCV3 & FCV4 & FCV5 & FCV6 & FCV7 \\
\hline FCV1 & 1.000 & - & - & - & - & - & - \\
FCV2 & $.620^{* *}$ & 1.000 & - & - & - & - & - \\
FCV3 & $.448^{* *}$ & $.452^{* *}$ & 1.000 & - & - & - & - \\
FCV4 & $.489^{* *}$ & $.502^{* *}$ & $.599^{* *}$ & 1.000 & - & - & - \\
FCV5 & $.450^{* *}$ & $.515^{* *}$ & $.333^{* *}$ & $.465^{* *}$ & 1.000 & - & - \\
FCV6 & $.378^{* *}$ & $.378^{* *}$ & $.626^{* *}$ & $.540^{* *}$ & $.375^{* *}$ & 1.000 & - \\
FCV7 & $.411^{* *}$ & $.460^{* *}$ & $.616^{* *}$ & $.577^{* *}$ & $.476^{* *}$ & $.738^{* *}$ & 1.000 \\
\hline
\end{tabular}

to COVID-19. Similarly, the FCV-19S was also positively correlated with the general anxiety disorder $(r=.458, p<.01)$.

\section{Confirmatory Factor Analysis}

A confirmatory factor analysis was performed to assess the single factor structure of the Urdu version of the FCV-19S scale (Table 5). The results show that fit indices are all within the acceptable limit:

$\left[\chi^{2}(9, N=501)=32.101, p<.05 ; \mathrm{RMSR}=.037 ; \mathrm{RMSEA}=.072 ; \mathrm{GFI}=.982 ; \mathrm{AGFI}=.944 ;\right.$ $\mathrm{TLI}=.967$; CFI $=.986]$. The factor loadings of the Urdu version of the FCV-19S were found to be statistically significant, ranging from 0.59 to 0.80 . We also calculated AVE and CR for the Urdu version of the FCV-19S. The values of $\mathrm{AVE}=.50$ and $\mathrm{CR}=.874$ indicate an evidence of construct reliability (Fig. 1).

\section{Mean Differences in FCV-19S as a Function of Socio-Demographic Characteristics}

The results of an independent sample $t$ test and a one-way ANOVA are presented in Table 6 . The findings show that there is a statistically significant mean difference $(t=4.086, p<0.001)$ in the FCV-19S between males $(M=17.73, \mathrm{SD}=5.31)$ and females $(M=19.76, \mathrm{SD}=5.72)$. Female respondents were more frightened due to the outbreak of novel coronavirus compared to male members of the society. There were also significant mean differences $(t=-2.709$, $p<.001)$ between married $(M=19.24, \mathrm{SD}=5.3)$ and unmarried people $(M=17.90, \mathrm{SD}=$ 5.20 ) in FCV-19S. We also found that unemployed people had higher scores on the FCV-19S compared to employed people. The findings also indicate that young adults had higher scores on the FCV-19S than middle-aged and elderly people.

Table 4 Factor loadings and Cronbach's alpha results

\begin{tabular}{llll}
\hline & Factor loadings & Cronbach's alpha if item deleted & Corrected-item total correlation \\
\hline FCV1 & 0.594 & .840 & .493 \\
FCV2 & 0.642 & .835 & .530 \\
FCV3 & 0.800 & .807 & .716 \\
FCV4 & 0.744 & .806 & .732 \\
FCV5 & 0.664 & .834 & .541 \\
FCV6 & 0.734 & .822 & .621 \\
FCV7 & 0.750 & .826 & .601 \\
\hline
\end{tabular}


Table 5 Confirmatory factor analysis

\begin{tabular}{lll}
\hline Psychometric testing & Value & Suggested cutoff \\
\hline Internal consistency (Cronbach's $\alpha)$ & 0.846 & 0.7 \\
Confirmatory factor analysis (CFA) & & Non-significant \\
$\chi 2(d f)$ & $32.101(9)^{*}$ & $\geq .95$ \\
Goodness of fit (GFI) & .982 & $\geq .90$ \\
Adjusted goodness of fit (AGFI) & .944 & $\geq .90$ \\
Comparative fit index (CFI) & .986 & $\geq .90$ \\
Tucker-Lewis index (TLI) & .967 & $<.08$ \\
Root mean square error of approximation (RMSEA) & .072 & $<.08$ \\
Root mean square residual (RMSR) & .037 & $\geq .50$ \\
Average variance extracted (AVE) & .500 & $\geq .60$ \\
Composite reliability (CR) & .874 & \\
\hline
\end{tabular}

\section{Discussion}

It is critical to mitigate fears of COVID-19 in order to better plan prevention and mitigate the health and social consequences of fear and anxiety in people, especially the vulnerable and

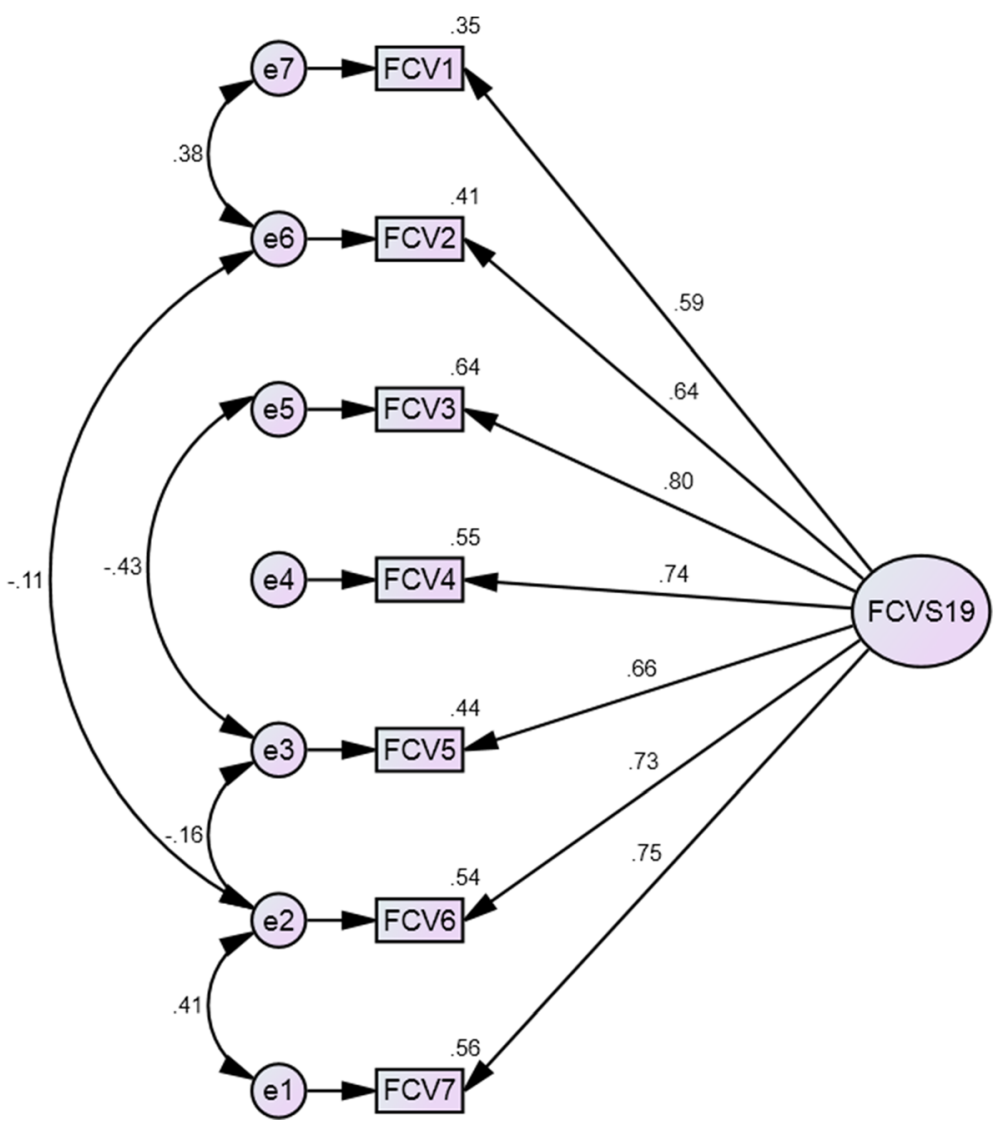

Fig. 1 Factor structure of the FCV-19S scale in Urdu 
Table 6 Effect of demographic variables on FCV-19S

\begin{tabular}{|c|c|c|c|c|}
\hline \multirow{2}{*}{$\begin{array}{l}\text { Variables } \\
\text { Gender }\end{array}$} & \multirow[t]{2}{*}{$N$} & \multirow{2}{*}{$\begin{array}{l}\mathrm{FCV}-19 \mathrm{~S} \\
\mathrm{M} \pm \mathrm{SD}\end{array}$} & \multicolumn{2}{|c|}{$95 \%$ confidence interval of the difference } \\
\hline & & & Upper & Lower \\
\hline Female & 208 & $19.76+5.721$ & 1.055 & 3.010 \\
\hline Male & 293 & $17.73+5.314$ & & \\
\hline$t$ value & & $4.086^{\text {*承 }}$ & df & 499 \\
\hline \multicolumn{5}{|l|}{ Marital status } \\
\hline Not married & 249 & $17.90+5.195$ & -.2 .312 & -.368 \\
\hline E married & 252 & $19.24 \overline{+} 5.863$ & & \\
\hline$t$ value & & $-2.70 \overline{9}^{* *}$ & df & 499 \\
\hline \multicolumn{5}{|l|}{ Employment status } \\
\hline Unemployed & 284 & $17.90+5.200$ & -2.532 & -.575 \\
\hline Employed & 217 & $19.45+5.922$ & & \\
\hline$t$ value & & $-3.199^{* *}$ & df & 499 \\
\hline \multicolumn{5}{|l|}{ Age } \\
\hline Up to 25 years & 195 & $19.59+5.860$ & & \\
\hline $26-50$ years & 273 & $18.11 \mp 5.334$ & Between the groups & 431.290 \\
\hline 51 years and above & 33 & $16.30 \mp 4.654$ & Within the groups & $15,093.444$ \\
\hline$f$ value & & $7.115^{-}$ & Total & $15,524.735$ \\
\hline
\end{tabular}

$* * p<.01, * * * p<.001, M=$ mean, $\mathrm{SD}=$ standard deviation

marginalized groups of society. The development of the FCV-19S scale has been valuable in expediting research across the world (Broche-Pérez et al. 2020). Our study has its limitations in that we were dependent on online sampling, and, therefore, the results may not be generalizable. In addition, the responses are based on perceptions, and there may be a source bias effect. However, this study has its strengths, in that it has confirmed the use of this scale in Urdu. The majority of people across Pakistan speak the official Urdu language despite the presence of multiple provincial languages throughout the country (Rahman 2006). It would not be wrong to say that the Urdu language has revived in recent years due to post-Colonial and nationalistic debates (Shamim 2008). The ability to type in Urdu on social media platforms and promote Urdu through digital means has also increased cultural attachment in the population and has facilitated increased usage.

Overall, our findings are similar to previous research using the FCV-19S scale. The internal consistency of the Urdu version of the FCV-19S was .846, which is slightly higher than that reported for the original scale $(\alpha=.82)$ (Ahorsu et al. 2020). However, this value is less than that reported for Italian $(\alpha=.87)$ (Soraci et al. 2020), Bangla $(\alpha=.87)$ (Sakib et al. 2020), Turkish $(\alpha=.85$ ), (Satici et al. 2020), and Arabic versions (Alyami et al. 2020). Our study also shows that the Urdu version of the FCV-19S scale has good concurrent validity, as demonstrated by a significant positive correlation with preventive behavior related to COVID-19, and general anxiety disorder, as well as acceptable construct validity, as demonstrated by the CFA results.

We now recommend repeat and longitudinal studies across the country, in order to facilitate identification of the prevalence of fear and policy planning for the alleviation of fear, and the training of healthcare practitioners, government officers, legal authorities, media, civilians, and the online community in helping to reduce fear and anxiety in the public.

We also found in this study that the following socio-demographic groups in the KPK province experience great fear of COVID-19: women, married people, unemployed people, and younger people. Gender research from the KPK confirms that women generally experience more fear when faced with health problems, due to the following: permission and mobility issues related to 
accessing healthcare when sick (Ali et al. 2016; Saeed and Farooq 2017); low literacy, and lack of health awareness and health information (Khan et al. 2013); poverty and financial barriers to health access (Qureshi et al. 2012); and the inherent maternal instinct and care emotions felt for family and children when risk of infection and disease is high (Shagufta and Shams 2019). Married people may suffer fear in times of pandemic and national uncertainties due to deterioration in family life and wellbeing (Ornell et al. 2020), risk of violence and abuse (Peterman et al. 2020), employment, loss of family income and household food insecurity (Loopstra 2020), and loss of spouse or fertility (Okwun and Siraj 2010).

With regard to unemployed people, they may experience great fear due to a reduced possibility of being recruited due to the decline in economic activity caused by lockdown and social distancing (Mamun and Ullah 2020). We recommend serious attention to support and alleviate the fears of disadvantaged populations during and after the pandemic. Certain critical areas that require attention include income generation and cash transfers, job stability and inflation control, and online counseling and therapy. It is also recommended that further studies attempt to include more socio-demographic characteristics related to co-morbidity and multi-morbidity in order to assess if the fear is also due to current and previous health burden. Variables related to "fear of public stigma" and "having a relative with COVID-19" may also be useful in identifying other factors that may influence fear and also in ascertaining any moderating effects on fear.

Acknowledgments We acknowledge friends and colleagues who helped us circulate this survey in difficult times as well as the respondents. We are also indebted to the linguistic expert who assisted us in translation.

\section{Compliance with Ethical Standards}

Conflict of Interest The authors do not have any conflict of interest.

\section{Appendix A}

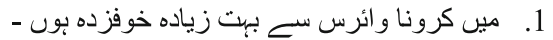

$$
\begin{aligned}
& \text { 2. }
\end{aligned}
$$

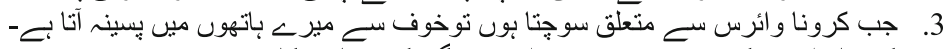

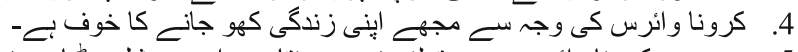

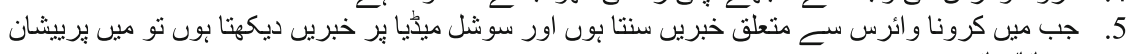

$$
\begin{aligned}
& \text { بوجاتا/جاتى بون- }
\end{aligned}
$$

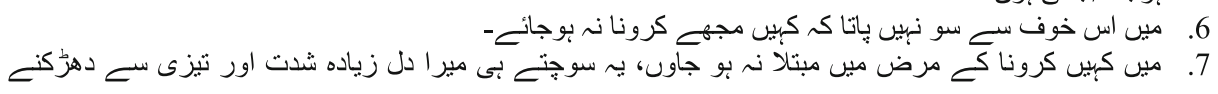

$$
\begin{aligned}
& \text { لكثنا بـ }
\end{aligned}
$$

\section{References}

Ahmad, M. (2010). Implications of the war on terror for Khyber Pukhtunkhwa, Pakistan. J Journal of Critical Globalisation Studies, 3.

Ahorsu, D. K., Lin, C.-Y., Imani, V., Saffari, M., Griffiths, M. D., Pakpour, A. H. J. I. J. o. M. H., \& Addiction. (2020). The fear of COVID-19 scale: development and initial validation. 
Ali, H., Ali, A., Mahmood, Q. K., Jalal, A., \& Ali, S. R. (2016). Antenatal care: Accessibility issue among Pakhtun women in Malakand, Pakistan. J Methodology, 10, 362-366.

Alyami, M., Henning, M., Krägeloh, C. U., \& Alyami, H. J. I. J. o. M. H. (2020). Psychometric evaluation of the Arabic version of the Fear of COVID-19 Scale. J International Journal of Mental Health Addiction, 1.

Broche-Pérez, Y., Fernández-Fleites, Z., Jiménez-Puig, E., Fernández-Castillo, E., \& Rodríguez-Martin, B. C. (2020). Gender and fear of COVID-19 in a Cuban population sample. International Journal of Mental Health and Addiction, 1-9.

Byrne, B. M., \& Campbell, T. L. (1999). Cross-cultural comparisons and the presumption of equivalent measurement and theoretical structure: A look beneath the surface. Journal of Cross-Cultural Psychology, $30(5), 555-574$.

DeVellis, R. F. (2016). Scale development: Theory and applications (4th ed.). SAGE.

Ferketich, S. (1991). Focus on psychometrics. Aspects of item analysis. Research in Nursing \& Health, 14(2), $165-168$.

Fineberg, N., Van Ameringen, M., Drummond, L., Hollander, E., Stein, D., Geller, D., . . Zohar, J. (2020). How to manage obsessive-compulsive disorder (OCD) under COVID-19: A clinician's guide from the International College of Obsessive Compulsive Spectrum Disorders (ICOCS) and the obsessivecompulsive research network (OCRN) of the European College of Neuropsychopharmacology. $J$ Comprehensive Psychiatry.

Grare, F., \& Maley, W. (2011). The afghan refugees in Pakistan. J Middle East Institute. Refugees Cooperation.

Haider, B., \& Jameel, S. (2017). Geneses, causes, and ramification of militancy in FATA in the post $9 / 11$ scenario.

Khan, N., Khan, S., Khan, N., \& Khan, S. (2013). Factors affecting utilization of maternal and child health services: District swat KPK Pakistan. J International Journal of Innovative Research development, 2(8).

Khan, A. A., Marwat, S. K., Noor, M. M., \& Fatima, S. (2015). Reliability and validity of Beck depression inventory among general population in Khyber Pakhtunkhwa, Pakistan. J Journal of Ayub Medical College Abbottabad, 27(3), 573-575.

Khan, S. F., Ullah, F., Khan, M. K., Raza, A. J. S., \& Shah, H. J. I. J. o. B. M. S. (2017). Effect of social media addiction on compliance in the patients of district Bannu, Khyber PakhtunKhwa. J International Journal of Basic Medical Sciences Pharmacy, 6(2).

Lei, P. W., \& Wu, Q. (2007). Introduction to structural equation modeling: Issues and practical considerations. Educational Measurement: Issues and Practice, 26(3), 33-43.

Lin, C. Y. (2020). Social reaction toward the 2019 novel coronavirus (COVID-19). Social Health and Behavior, $3(1), 1$.

Loopstra, R. (2020). Vulnerability to food insecurity since the COVID-19 lockdown. The Food Foundation.

Mamun, M. A., \& Griffiths, M. D. (2020). First COVID-19 suicide case in Bangladesh due to fear of COVID-19 and xenophobia: Possible suicide prevention strategies. Asian Journal of Psychiatry, 51, 102073.

Mamun, M. A., \& Ullah, I. (2020). COVID-19 suicides in Pakistan, dying off not COVID-19 fear but poverty?the forthcoming economic challenges for a developing country. Brain, Behavior, Immunity., 87, 163-166.

Mehboob, S. (2011). Governance and militancy in Pakistan's Khyber Pakhtunkhwa Province. Washington, DC: $\mathrm{J}$ Center for Strategic International Studies.

Okwun, K. C., \& Siraj, S. (2010). Family and marriage counseling and HIV/Aids pandemic in Nigeria.

Ornell, F., Schuch, J. B., Sordi, A. O., \& Kessler, F. H. P. (2020). "Pandemic fear" and COVID-19: Mental health burden and strategies. Brazilian Journal of Psychiatry, 42(3), 232-235.

Pakpour, A., \& Griffiths, M. (2020). The fear of COVID-19 and its role in preventive behaviors. Journal of Concurrent Disorders.

Pakpour, A. H., Griffiths, M. D., Chang, K. C., Chen, Y. P., Kuo, Y. J., \& Lin, C. Y. (2020). Assessing the fear of COVID-19 among different populations: A response to Ransing et al.(2020). Brain, Behavior, and Immunity.

Peterman, A., Potts, A., O’Donnell, M., Thompson, K., Shah, N., Oertelt-Prigione, S., \& van Gelder, N. (2020). Pandemics and violence against women and children. J Center for Global Development working paper, 528.

Qureshi, M. I., Saleem, M. A., Shah, M., Abbas, Z., Qasuria, A. W., \& Saadat, U. R. (2012). Ensuring the role and impact: Reaching the poorest while alleviating the poverty by micro finance in Dera Ismail Khan KPK Pakistan. Developing Country Studies, 2(4), 38-44.

Rahman, T. (2003). Language policy, multilingualism and language vitality in Pakistan. In A. Saxena \& L. Borin (Eds.), Lesser-known languages of South Asia-status and policies, case studies and applications of information technology (pp. 73-106). Berlin: Mouton de Gruyter.

Ramaci, T., Barattucci, M., Ledda, C., \& Rapisarda, V. (2020). Social stigma during COVID-19 and its impact on HCWs outcomes. Sustainability, 12(9), 3834.

Reznik, A., Gritsenko, V., Konstantinov, V., Khamenka, N., \& Isralowitz, R. (2020). COVID-19 fear in Eastern Europe: Validation of the fear of COVID-19 scale. J International Journal of Mental Health Addiction, 1. 
Saeed, A., \& Farooq, S. (2017). "I Can’t go out": Mobility obstacles to women's access to HIV treatment in KPK, Pakistan. J Journal of the Association of Nurses in AIDS Care, 28(4), 561-574.

Sakib, N., Bhuiyan, A. I., Hossain, S., Al Mamun, F., Hosen, I., Abdullah, A. H., . . . Hossain, M. (2020). Psychometric validation of the Bangla fear of COVID-19 scale: Confirmatory factor analysis and Rasch analysis. J International Journal of Mental Health Addiction.

Satici, B., Gocet-Tekin, E., Deniz, M. E., \& Satici, S. A. (2020). Adaptation of the fear of COVID-19 scale: Its association with psychological distress and life satisfaction in Turkey. J International Journal of Mental Health Addiction, 10.

Shagufta, S., \& Shams, S. (2019). Prevalence, differences, and predictors of anxiety and depression among pregnant and non-pregnant women in Peshawar Khyber Pakhtunkhwa Pakistan. J FWU Journal of Social Sciences, 13(1), 167-176.

Shamim, F. (2008). Trends, issues and challenges in English language education in Pakistan. Asia Pacific Journal of Education, 28(3), 235-249.

Soraci, P., Ferrari, A., Abbiati, F. A., Del Fante, E., De Pace, R., Urso, A., \& Griffiths, M. D. (2020). Validation and psychometric evaluation of the Italian version of the fear of COVID-19 scale. J International Journal of Mental Health Addiction, 1-10.

Spitzer, R. L., Kroenke, K., Williams, J. B., \& Löwe, B. (2006). A brief measure for assessing generalized anxiety disorder: The GAD-7. Archives of Internal Medicine, 166(10), 1092-1097.

Tsipropoulou, V., Nikopoulou, V., Holeva, V., Nasika, Z., Diakogiannis, I., Sakka, S., . . Parlapani, E. (2020). Psychometric properties of the Greek version of FCV-19S. J International Journal of Mental Health Addiction, 1.

Waris, A., Khan, A. U., Ali, M., Ali, A., \& Baset, A. (2020). COVID-19 outbreak: Current scenario of Pakistan. J New Microbes New Infections, 100681.

World Health Organization. (2020). Infection prevention and control during health care when COVID-19 is suspected: Interim guidance, 19 march 2020. Retrieved from.

Yu, D. S., Lee, D. T., \& Woo, J. (2004). Issues and challenges of instrument translation. Western Journal of Nursing Research, 26(3), 307-320.

Publisher's Note Springer Nature remains neutral with regard to jurisdictional claims in published maps and institutional affiliations.

\section{Affiliations}

\section{Qaisar Khalid Mahmood $^{1} \cdot$ Sara Rizvi Jafree ${ }^{2} \cdot$ Waheed Ahmad Qureshi $^{3}$}

1 Department of Sociology, International Islamic University, Islamabad, Pakistan

2 Department of Sociology, Forman Christian College (A Chartered University), Zahoor Elahi Road, Gulberg 3, Lahore 54600, Pakistan

3 Department of Sociology, Anadolu Üniversitesi Yeșiltepe, Yunus Emre Kampüsü, 26470 Tepebaşı, Eskișehir, Turkey 